\title{
Sustainable desalination: integration of power supply with renewable energy sources
}

\author{
M. Marini ${ }^{1}$, C. Palomba ${ }^{2}$, P. Rizzi ${ }^{1}$, E. Casti ${ }^{1}$, A Marcia $^{1}$, M. Paderi ${ }^{2}$ \\ ${ }^{1}$ Department of Architecture, Planning and Design \\ DADU, University of Sassari \\ Palazzo del Pou Salit, Piazza Duomo 6, 07041 Alghero (SS), Italy \\ Phone/Fax number +39079 9720409, e-mail: $\underline{\text { marini@ uniss.it , ecasti@uniss.it }}$ \\ ${ }^{2}$ Department of Mechanical, Chemical and Materials Engineering, \\ DIMCM, University of Cagliari, \\ Via Marengo, 2 Cagliari 09123, Italy \\ Phone/Fax number +3907067557441, e-mal: chiara.palomba@dimcm.unica.it
}

\begin{abstract}
The production of fresh water through the desalination of brackish water or seawater looks a reliable solution to satisfy the water needs of human settlements in areas with enduring water scarcity.

However, when a desalination plant is called to work with large seasonal fluctuations in fresh water demand, as in areas with a strong tourist season, daily and seasonal variability of water demand mismatch with the usual needs of plants operation which ensure the maximum efficiency and the minimum cost of desalinated water. In addition, the necessary intake devices for all these technologies have always an impact on the area where the plant is installed also in terms of chemicals use, concentrated brine release. The proposed case study concerns the Asinara Island, whose entire surface and coastal area is now a national park. In this context the paper analyses the complexity of desalination plants design and operation for a respectful use of the soil and a wide seasonal swing of water demand. It aims at selecting the most energy efficient solution endowed with a good sustainability by obtaining power with renewable sources of energy [1],[2]. The analysis is further developed taking into account the impact of governance actions aiming at a more responsible use of water resources, including the reuse of wastewater of sewage for irrigation. A mathematical model is presented and applied: it allows to analyse the integrated system performance to search for the optimum solution, once the time trends, statistical water demand and renewable energy sources (wind, solar) availability, the features of the desalination system (Reverse Osmosis or Mechanical Vapour Compression), the capacities and catching areas of the basins have been defined and calculated.
\end{abstract}

\section{Key words}

Desalination, renewable energy sources, variable operation, protected area, stand alone systems.

\section{Introduction}

Asinara Island first becomes Marine Protected Area in August 2002 by a Decree of the Ministry for the Environment, Land and Sea; shortly after becomes
National Park by a Presidential Decree on 3rd October 2002. The current and future activities on the island are described in the "Plan of the Park" (hereinafter referred to as PPA), a document that has proactive but nonprescriptive value and "constitutes the guidance, discipline and management framework for the actions of individuals and institutions that operate in the territory of the Park".

The cultural options provided in the PPA are all united by a vision of preservation of the natural, environmental and historical heritage in its physical, biological, ecological, human, social and economic integrity through an organization of the territory functional for this purpose. The consequent development policies proposed in the PPA include not only the restoration and maintenance of natural, ecological and environmental structures, conservation of plant and animal species, emerged and submerged landscape protection but also the promotion of educational, training and scientific research as well as tourism activities compatible with the purposes of protection and restoration of ecological and hydrological balance and maintaining the memory heritage.

A previous work enabled to evaluate the water demand based on two different scenarios for park development. In the same work a possible equipment has been dimensioned to satisfy water needs using desalination as an integration of the natural fresh water availability from rain. The present work, aims at a thorough investigation of energy needs and at finding the best way to supply such energy requirements with renewable energy sources considering on one side the minimum impact on the park territory and on the other side the entity and timing of energy demand from the desalination plant.

\section{The Proposed Integrated Water System}

Since it became National Park in 2002, a process of gradual opening up of the island started to allow recovery 
and resettlement of abandoned buildings in historic towns. However this process is bound to the adoption of shared and respectful rules of management for the use of land. The PPA has adopted as address the limitation to a cautious and conservative recovery of existing buildings and settlement structures of the three urban units (Cala d'Oliva, the Cala Reale and Trabuccato). In these urban units, the main functions including hosting activities, infrastructures and services, for the social and economic development of the Park, are located.

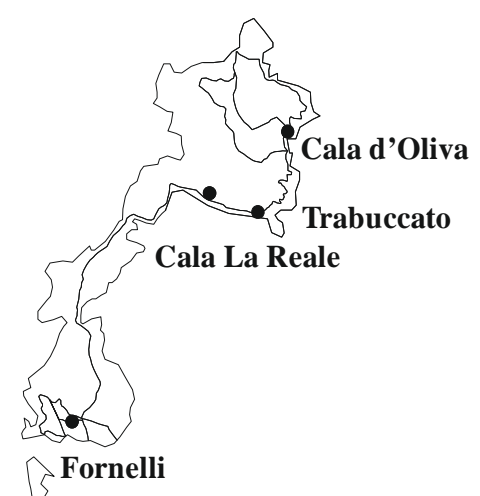

Fig. 1. Asinara Island

As far as the agriculture and livestock are regarded, it is interesting to note that these activities were initiated to support the self-supply of inmates and staff of the penal colonies in the late '800; they were then left following the orders of the maximum security prison. The PPA envisages the recovery of such assets according to a model of subsistence farming intended for self consumption, with the simultaneous recovery of the rural landscape and the farming model.

The island includes autonomous systems for each major urban area consisting of storage basin, water purifying system and wastewater treatment unit. They originate from the past history and management of the island water system, until the closure of the prison, At present almost all of these devices, exclusive of the reservoirs (even if not exempt from eutrophication problems), are completely or at least partially compromised.

Table I. - Asinara's artificial reservoirs

\begin{tabular}{|c|c|c|c|}
\hline $\begin{array}{c}\text { Artificial } \\
\text { reservoir }\end{array}$ & $\begin{array}{c}\text { Volume } \\
{\left[\mathrm{m}^{3}\right]}\end{array}$ & $\begin{array}{c}\text { Elevation a.s.l. } \\
{[\mathrm{m}]}\end{array}$ & $\begin{array}{c}\text { Catchment } \\
\text { surface }[\mathrm{ha}]\end{array}$ \\
\hline Cala d'Oliva & 13000 & 80 & 157.3 \\
\hline Campu Perdu & 15000 & 10 & 57.3 \\
\hline Fornelli & 50000 & 30 & 77.5 \\
\hline Santa Maria & 15000 & 10 & 117.8 \\
\hline
\end{tabular}

\section{A. Water Needs}

The estimation of water needs has been implemented on a monthly basis: this leads to a sufficient level of time detail for the purpose of the analysis and corresponds to that of the majority of the statistical data used. Water requirements of resident and daily floating population were calculated according to the total capacity assumed in the PPA and the statistics of tourist inflow to Sardinia. The parameters here considered to estimate the water consumption for industrial (handicraft, farm and livestock products processing) and agricultural activities were assumed consistent with the subsistence policy planned by PPA. Seasonal fluctuations play an essential role in the demand pattern, they have to be accurately modelled as they justify the desalination plant and influence its achievement [3].

\section{B. Water Availability}

The only source of water is due to the availability of the four storage reservoirs, made between the years '70 and ' 80 , to provide the drinking water supply for the different prison structures and to cope with the demands for irrigated agriculture and livestock. Their locations and characteristics are given in Figure 1 and Table 1. For the evaluation of the collected rain water, the precipitation values from the meteorological database data.org and the climate-related data of the close-by municipality of Stintino as well as the surfaces of the four catchment areas and the runoff coefficient due to the specific morphology of the territory have been used. It was considered the possibility to take advantage of treated wastewaters to reduce the irrigation needs as action of governance. The civil needs related to irrigation of green areas, cleaning streets and squares can be reduced too.

\section{Water Balance}

To match the availability with the needs, the most rational solution for self-sustainment appears to be the inter-connection of the water systems of the three urban areas above considered. Therefore in a first water balance analysis was carried out with the assumption of a fully integrated network i.e., a system ensuring a total balance of resources and needs. Considering the full availability of raw fresh water in the reservoirs, but setting a maximum limit to their emptying of $70 \%$, a shortage of availability in summer was revealed. This shortage could be balanced out by sea water desalination and the corresponding size of the desalination plant was evaluated. A capacity of $430 \mathrm{~m}^{3} \mathrm{day}^{-1}$ and $300 \mathrm{~m}^{3}$ day $^{-1}$ was found for the two scenarios "reference" and "governance". Fig 2 shows the monthly fresh water balance for the governance case.

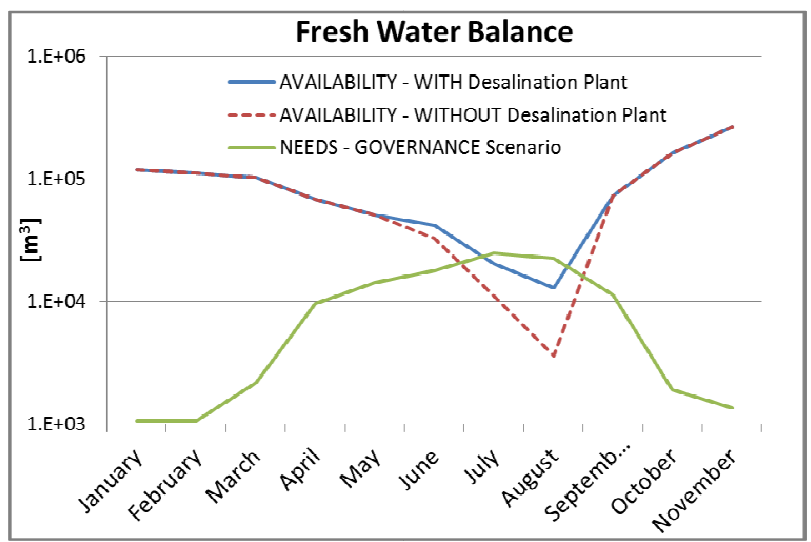

Fig. 2. Fresh Water balance for "governance" scenario

Since the hypothesis of a complete connection of the thee reservoirs, as currently non-existent, is certainly complex and expensive, also in relation to the specific morphology of the island, the study moved on to balancing each urban 
area individually in order to assess which connections, in the scenarios considered, were actually necessary or appropriate. Comparative analyses between the total water balance and the specific balance of the three single areas showed a strong imbalance between the high availability in the south of the Island, related to the capacity of the basins of Fornelli and Santa Maria, and the scarcity in the north, due to the needs posed by human activities in the two areas in such a section of the Island.

The main consequence from this imbalance between availability and demand in the three areas considered is the need to allow a transfer of raw water from Fornelli - Santa Maria to the other two distribution areas. However, in summer the compensation is not sufficient and the installation of a desalination plant is proposed, specifically intended to balance out the summer water deficit of the two north areas with a annual load work equal to three months as the storage of the produced fresh water is problematic. From a logistical and infrastructural standpoint, also considering the landscape constraints, the optimal location of the desalination plant should be near La Reale.

In summary, the results of the analysis recommend that the infrastructure necessary to ensure the satisfaction of the water demand throughout the island should provide, for both scenarios:

- a line of raw water from the south basins to the north basin in La Reale to allow the partial integration of the deficit between demand and needs in summer;

- a desalination plant to cover for the residual deficit;

- a line of desalinated water between La Reale and Cala d'Oliva.

\section{Energy Needs Evaluation}

Once the requirements and availability scenarios have been defined and the infrastructure necessary to achieve the water balance has been sized, the energy consumption of such plants, including pumping energy in the interconnection lines, has been evaluated. For the desalination plant two industrial technologies, both of them powered exclusively with electricity, have been considered: reverse osmosis (RO) [4] and mechanical vapour compression (MVC) [5].

The raw and fresh water have to be pumped in a circuit with a variable height with respect to the sea level. Therefore, to evaluate the pumping energy, not only the losses along the piping have been considered but also the energy needed to go beyond altitude gaps. Such an energy given to move the fluid upward can be recuperated when fluid moves downward by providing the system with an enegy exchange machine. Since it is a matter of small amount with respect to the other energy contributions, the energy for potabilisation hasn't been included in the calculation.

The desalination plant sizing is based upon the sea water characteristics. The physical and thermodynamic properties of seawater and brine have been evaluated by functions implemented in a Matlab code based upon experimental correlations developed by MIT [6]. The data on salinity and temperature have been obtained through the use of database MEDAR/Medatlas II. The composition and quality (turbidity, presence of suspended solids and organic substances) were assumed equal to the average of the Mediterranean Sea. [8].

Once seawater characteristics have been determined in terms of composition, the energy demand of the two proposed desalinating technologies has been calculated with the aid of in house developed Matlab codes. In the energy balance all demands have been taken into account including salted water abduction, clear water dispatching to the water basins and brine disposal.

Moreover, the plants require pre and post treatment of water, therefore the required energy for them has been considered since they are integral parts of the whole plant.

As for the MVC technology, the plant behavior was simulated by a stationary model developed in Matlab environment on the base of the work proposed by ElDessouky et al. in [5]; however the analyticalexperimental correlations proposed in [6] were used, regarding the thermodynamic properties of seawater and brine and those in [26] for the distillate (in the liquid and vapour state). Further integrations concern the heat exchange coefficients of evaporators, tube and plate heat exchangers for which reference data are the correlations given in [9]. Among the possible configurations for such a technology, in relation to the reduced capacity of the plant, it has been decided to adopt the single effect solution. This configuration, although hindered by lower efficiency values with respect to multi-effect configurations, allows to have not too small ( few degrees) temperature differences in the evaporator while keeping a reasonable compression ratio. Consequently, the system presents contained heat exchange surfaces and, at the same time, the operating conditions of the compressor are not critical, both factors in favor of the containment of the overall cost of the plant. However, the single effect solution, in which all the distillate production arises in a single effect, requires the compressor to work with higher flow rates. This aspect, increasing the compressor size, is unfavorable for the overall cost of the system.

The main plant specifics are given in Table II.

$$
\text { Table II. - MVC plant specs }
$$

\begin{tabular}{|c|c|}
\hline Capacity $\left[\mathrm{m}^{3} /\right.$ day $]$ & 302.9 \\
\hline Number of effects & 1 \\
\hline Brine maximum temperature $\left[{ }^{\circ} \mathrm{C}\right]$ & 65 \\
\hline Seawater absolute salinity [ppm] & 38300 \\
\hline Brine disposal absolute salinity [ppm] & 70000 \\
\hline Feed flow $[\mathrm{kg} / \mathrm{s}]$ & 7.73 \\
\hline Effect exchange area $\left[\mathrm{m}^{\wedge} 2\right]$ & 1540 \\
\hline Overall exchange area $\left[\mathrm{m}^{\wedge} 2\right]$ & 1595 \\
\hline Compressor compression ratio & 1.192 \\
\hline Compressor inlet volumetric flow $\left[\mathrm{m}^{\wedge} 3 / \mathrm{s}\right]$ & 22.7 \\
\hline MVC - Electric power $[\mathrm{kW}]$ & 129.5 \\
\hline Pretreatment - Electric power $[\mathrm{kW}]$ & 1.81 \\
\hline Specific energy $\left[\mathrm{kWh} / \mathrm{m}^{\wedge} 3\right]$ & 10.40 \\
\hline Plant cost $[k €]$ & 722 \\
\hline MVC plant cost amortization [€/m^3] & 2.922 \\
\hline $\begin{array}{l}\text { Operation and maintenance cost (energy } \\
\left.\text { excluded) [ } € / \mathrm{m}^{\wedge} 3\right]\end{array}$ & 0.35 \\
\hline
\end{tabular}


The performance of the reverse osmosis plant was obtained through a computer code, implemented in Matlab environment, based on the mathematical model proposed by Avlonitis [10], [11]. The model allows to simulate the behavior in the steady state of the chosen configuration of the filter elements by calculating the performance of each membrane in accordance with the methodology developed by Avlonitis and others [4]. For the estimation of the diffusion coefficient, reference was made to the experimental data available in the literature on aqueous solutions of $\mathrm{NaCl}$ [7]. In consequence of the low flows involved, the system chosen was a single stage filtration device with a reduced number of elements for each pressure vessel (Table III). To feed the vessels in parallel the configuration includes a high pressure pump in series to an centrifugal turbocharger energy recovery system; the choice is driven by the fact that even if such a system has a lower recovery ratio (permeated flow of input flow rate) than those normally adopted for the installations of larger plants, it allows to obtain an appropriate energy recovery from the outgoing brine and reduces the energy consumption of the main pump [12]. The choice of the pre-treatment system was made in respect of such features and of the ability to exploit an existing seawater intake close to the possible location of the plant. The pretreatment process was therefore considered as made of a chlorination, a $\mathrm{pH}$ adjustment using sulfuric acid (ASTM standard $D$ 4582), the addition of coagulant, an ultrafiltration system and a cartridge filter to protect reverse osmosis membrane, following the indication in the manual [13].

Table III. -RO plant specs

\begin{tabular}{|c|c|}
\hline Capacity $\left[\mathrm{m}^{3} /\right.$ day $]$ & 301 \\
\hline Number of stage & 1 \\
\hline Seawater absolute salinity [ppm] & 38300 \\
\hline Brine disposal absolute salinity [ppm] & 55200 \\
\hline Feed flow $[\mathrm{kg} / \mathrm{s}]$ & 10.23 \\
\hline Recovery factor & 0.35 \\
\hline $\mathrm{N}^{\circ}$ of membranes & 28 \\
\hline $\mathrm{N}^{\circ}$ vessels & 7 \\
\hline Active Membranes area $\left[\mathrm{m}^{\wedge} 2\right]$ & 737.8 \\
\hline RO - Electric power [kW] & 55.6 \\
\hline Pretreatment - Electric power $[\mathrm{kW}]$ & 5.1 \\
\hline Specific energy [kWh/m^3] & 4.84 \\
\hline Plant cost $[\mathrm{k} €]$ & 452 \\
\hline Plant cost amortization [€/m^3] & 1.659 \\
\hline $\begin{array}{l}\text { Operation and maintenance cost (energy } \\
\text { excluded) }\left[€ / \mathrm{m}^{\wedge} 3\right]\end{array}$ & 0.531 \\
\hline
\end{tabular}

\section{Plant management and intermittent renewable sources}

To satisfy the energy needs, with the perspective of enhancing the environmental sustainability of desalination, the use of renewable energy sources has been considered. Since the plant operation is intermittent, it has been estimated that an off-grid solution would bring higher installed power and the need for a storage system, while the possibility of local exchange makes the on-grid solution more interesting. The solution investigated includes the use of solar and wind energy.
The hydro electric solution was considered as well by doing an approximate evaluation of the potential of energy production with exceeding flows from existing reservoirs, i.e. with flows from too full reservoirs. Such a rough evaluation came from the available geodetic head, as compatible with the island morphology, losses along pipes and the average conversion efficiency. The sparse time resolution of rainfall data and the torrential-like character of streams involved an unreliable character of such an analysis so that it was not included in the energy balance later discussed. However in the diagrams of Fig. 3 and 4 the trend of the calculated potential has been drawn with a dotted line for sake of completeness.

The evaluation of the productive potential of the photovoltaic system was performed from data of global and diffuse radiation on a horizontal plane, relative to the site of interest, provided by the meteorological database Meteonorm. The calculation of the radiation incident on the modules was evaluated according to the common geometrical correlations which take account the relative motion between sun and earth as a function of time and the position relative to the earth of the module [14].

The yield of the modules, needed for the calculation of electricity from given radiation accident, was calculated according to the equation proposed in [14]. As far as the plant cost is concerned the data found in [15], were taken as reference; they regard turn-key plants rated for size. In the Table IV the dimensions in terms of overall surface of modules, the estimated cost of the plant and the unit production cost (per kWh of electricity output) are shown for the two PV plants required to meet the yearly need of the considered two desalination systems. In the same Table the amount of direct consumption and the amount of net energy metering are shown as well; for the latter also the gap of cost (per $\mathrm{kWh}$ ) between the drawn and ceded energy to the grid.

Table IV. - PV plants specs

\begin{tabular}{|l|l|l|}
\hline & MVC & RO \\
\hline Modules Azimuth & $0^{*}$ & $0^{*}$ \\
\hline Modules Inclination $\left[^{\circ}\right]$ & 20 & $20^{\circ}$ \\
\hline Overall modules area $\left[\mathrm{m}^{2}\right]$ & 1024.61 & 492.96 \\
\hline Energy production $[\mathrm{MWh} /$ year] & 292.77 & 140.86 \\
\hline Plantcost [k€] & 191.6 & 98.1 \\
\hline Energy cost [€/kWh] & 0.0895 & 0.0953 \\
\hline $\begin{array}{l}\text { Energy direct consumption } \\
{[\text { MWh/year] }}\end{array}$ & 101.15 & 48.98 \\
\hline Energy net metering [MWh/year] & 191.62 & 91.88 \\
\hline Energy cost(net metering) [€//kWh] & 0.1142 & 0.1200 \\
\hline
\end{tabular}

The prediction of the Energy output from wind source has been obtained with reference to the hourly samples of wind speed, temperature and absolute pressure, extracted by mean of a reanalysis through the software Vortex by "Vortex Factoria de Calculs", in turn based on the ERAInterim data provided by European Centre for MediumRange Weather Forecasts. The prediction of the annual energy production has been assessed on a monthly basis following the theoretical setting expounded in [14] and [16]. In order to satisfy the energy need yearly required by each of the two configurations of desalination plant, a 
specific model of commercial wind turbine has been selected, marked out by its power curve as provided in the constructor listing. The cost analysis has been developed in reference to the price trends related in the U.S. DOE report [17]. In Table $V$ the performance and the cost items of the different configurations are shown.

Table V. - Wind farm specs

\begin{tabular}{|l|l|l|}
\hline & MVC & RO \\
\hline Turbine Model & $\begin{array}{l}\text { Ciesse } \\
\text { Energia } \\
100313-B\end{array}$ & $\begin{array}{l}\text { Wind Energy } \\
\text { Solution } \\
\text { WES80 }\end{array}$ \\
\hline Rated power [kW] & 100 & 80 \\
\hline $\begin{array}{l}\text { Energy production } \\
{[\mathrm{MWh/year]}}\end{array}$ & 308.8 & 199.2 \\
\hline Plant cost [k€] & 250 & 200 \\
\hline Specific plant cost [€/kWh] & 0.1070 & 0.1325 \\
\hline $\begin{array}{l}\text { Energy cost - "net metering" } \\
\text { [€/kWh] }\end{array}$ & 0.1353 & 0.1400 \\
\hline $\begin{array}{l}\text { Enegy cost - "all-inclusive } \\
\text { rate" [€/kWh] }\end{array}$ & 0.1042 & 0.0889 \\
\hline $\begin{array}{l}\text { Energy direct consumed } \\
{[\mathrm{MWh/year]}}\end{array}$ & 47.9 & 30.32 \\
\hline $\begin{array}{l}\text { Energy net metering } \\
{[\mathrm{MWh/year]}}\end{array}$ & 244.87 & 110.54 \\
\hline
\end{tabular}

The comparison of energy needs and production are shown in Fig. 3 and 4 for the MVC technology and the RO technology respectively.

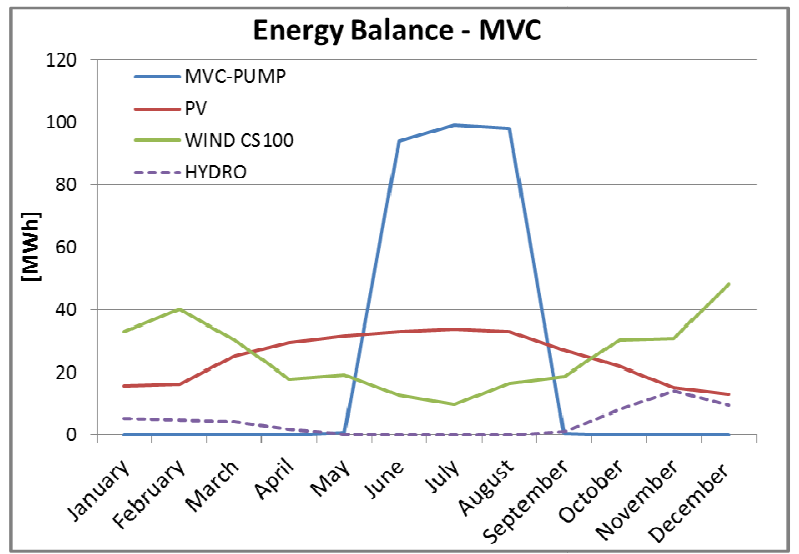

Fig 3 RES energy and water production along the year adopting MCV desalination

While the desalination plants operate at full power for three months, June through August, the renewable energy plants operate throughout the year with variable output. In order to compare thoroughly the different solutions proposed, it is necessary to evaluate the associated costs.

\section{Cost Analysis and final discussion}

As the estimated cost of the MVC plant the correlations reported in [9] for heat exchangers are an essential reference, while for the centrifugal compressor and pumps the reference data are those published on Matches site [18] and for the remaining components the correlations proposed by El-Sayed in [19]. These terms of cost were discounted to 2014 by the Chemical Plant Cost Index published by Chemical Engineering (CEPCI) [20].

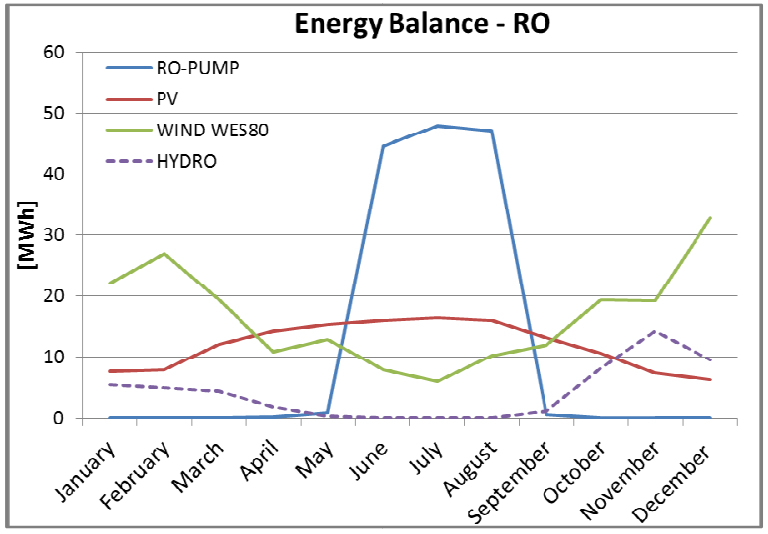

Fig 4 RES energy and water production along the year adopting RO desalination

The assessment of capital and operation costs for the reverse osmosis plant, energy expenses excluded, has been carried out thanks to the data drawn from the works of Kaldellis e Kondili [21] and of Malek [22]. Maintenance costs for membranes during plant stoppage were assumed as unimportant and neglected [23].

The calculation of the cost term regarding the plant amortization in $n$ years (assumed 20 year for both desalination systems and plants to exploit renewable sources RES) has been carried out through the French method (straight-line capital cost recovery) with an interest rate $i$ equal to $8 \%$ and taking an annual insurance rate $(A I R)$ equal to $1 \%$ :

$$
F C R=C C R+A I R=i \cdot \frac{(1+i)^{n}}{(1+i)^{n}-1}+A I R
$$

In calculating the specific energy cost the subsidizations for the use of RES, promoted by the Italian managing authority of the energy services, have been taken into account. In detail, for both photovoltaic and wind systems the net metering option ("scambio sul posto") has been considered; it allows to get an economic compensation, i.e. a tradeoff between the value of the produced energy which is given to the grid and the value of the energy which is drawn and consumed in a period different from that when the production occurs [24].

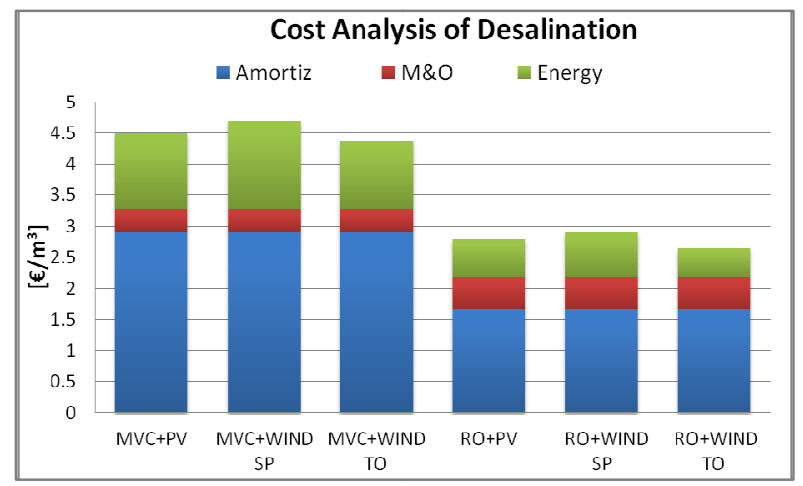

Fig. 5 Overall cost of desalinated water by various RES systems (SP: net metering, TO: all-inclusive rate) 
Alternately, as the wind energy production is concerned, there is the possibility of exploiting the subsidization of a all-inclusive rate called "Tariffa omnicomprensiva" which allows to obtain, for all medium and small size plants $(<1$ MW of rated capacity) a favorable remuneration for the energy given to the grid with respect to the outlays for the energy drawn from the grid and then consumed [25]. The overall desalination costs are shown in Fig. 5 for the different plant configurations and, just for wind source, for two alternative subsidizations. The reverse osmosis technology proves to have lower capital and energy costs but higher management costs if compared with mechanical vapor compression. It is worth noting that the energy costs depend on the relationship begun with the managing authority too and not only on the kind of renewable source if an on grid configuration is adopted.

\section{Conclusions}

Desalination could be considered as an extreme technical solution to cope with exceptional water shortages. But desalination plant can integrate profitably with renewable energy sources as wind and sun, with the electrical grid as well as with storage devices to get advantage of energy management. After analysing the water demand and needs of a small island of special environmental interest, an integrated system for water supply has been conceived and modelled. The performance of the desalinated system has been evaluated from a technical and economical point of view, comparing different configurations, to give some insight to the sustainability of desalination systems integrated with RES.

\section{Acknowledgement}

The present work is an integral part of a research project financed by Sardinia Region Law 7/2007 - annuity 2010 entitled "Models for energy and environmental impact reduction of fresh water supply from sea source, and governance modelling for alternative technologies integration in the coastal territory in harmony with landscape constraints".
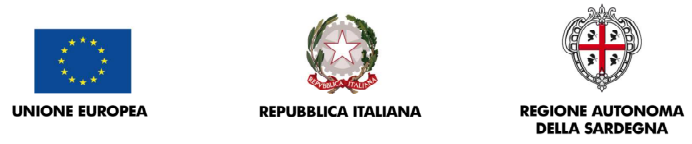

\section{References}

[1] C. Koroneos, A. Dompros, G. Roumbas, "Renewable energy driven desalination systems modeling", Journal of cleaner production vol. 15 (2007), pp 449-464

[2] E. Mathioulakis, V. Belessiotis, E. Delyannis, "Desalination by using alternative energy: review and state of the art", Desalination vol. 203 (2007), pp. 346-365

[3] C. Palomba, P. Rizzi, A. Marcia, M. Paderi, "Seawater desalination powered by renewable energy sources for sustenaible fresh water supply construction of a partaken process in a marine protected area", in proceedings of IV Simposio Internazionale "Il monitoraggio Costiero del Mediterraneo", Livorno June 12-14 2012, pp 69-76.

[4] S. A. Avlonitis, M. Pappas, K. Moutesidis "A unified model for the detailed investigation of membrane modules and RO plants performance", Desalination vol. 203, 2007,pp 218228, , Ed. Elsevier
[5] H. T. El-Dessouky, H. M. Ettouney, F. Al-Juwayhel, "Multiple effect evaporation - Vapour compression desalination processes", Trans IChemE vol. 78 Part A (2000) pp. 662-676

[6] M. H. Sharqawy, J. H. Lienhard V, S. M. Zubair, "Thermophysical properties of seawater: a review of existing correlations and data", Desalination and Water Treatment vol. 16 (2010) pp. 354-380

[7] [12] Victor M. M. Lobo "Mutual diffusion coefficients in aqueous electrolyte solutions", Pure \& Appl. Chern., Vol. 65, No. 12, 1993, pp. 2613-2640, IUPAC

[8] FILMTEC TM Reverse Osmosis Membranes Technical Manual, "Water Chemistry and Pretreatment: Feedwater Type and Analysis", Form No. 609-02010-1004, http://www.filmtec.com

[9] H. Saunders "Heat Exchanger" Ed. Longman (1988)

[10] S. Avlonitis, W.T. Hanbury, M. Ben Boudmar "Spiral wound modules perfomance. An analytic solution, Part I", Desalination vol. 81, 1991,pp. 191-208, Ed. Elsevier

[11] S. Avlonitis, W.T. Hanbury, M. Ben Boudmar "Spiral wound modules perfomance. An analytic solution, Part II", Desalination vol. 89, 1993, pp. 227-246, Ed. Elsevier

[12] Guirguis, Mageed Jean, "Energy Recovery Devices in Seawater Reverse Osmosis Desalination Plants" (2011), http://scholarcommons.usf.edu/etd/3135

[13] M. Chapman Wilbert, J. Pellegrino, J. Scott, Q. Zhang "Water treatment estimation routine-user manual", DesalR\&D report ${ }^{\circ} 49,1999$, U.S. DEPARTMENT OF THE INTERIOR - Bureau of Reclamation.

[14] D. Cocco, C. Palomba, P. Puddu, "Tecnologie delle energie rinnovabili", SGEditoriali, 2008

[15] Department of Management, Economics and Industrial Engineering of Politecnico di Milano, "Solar Energy Report 2014 - Il sistema industriale italiano nel business dell'energia solare", 2014

[16] R. Pallabazzer "Sistemi eolici”, Rubbettino, Editore, 2004

[17] R. Wiser, M. Bolinger "2012 WIND TECHNOLOGIES MARKET REPORT", U.S. DOE, Office of Energy Efficiency and Renewable Energy, Washington, D.C.

[18] http://matche.com/EquipCost/Compressor.htm

[19] El-Sayed, "Designing desalination systems for higher productivity", Ed. Elsevier (2001)

[20] Chemical Engineering Plant Cost Index (CEPCI), http://www.chemengonline.com/pci-home

[21] J.K Kaldellis, E.M. Kondili, "The water shortage problem in the Aegean archipelago islands cost-effective desalination prospect", Desalination vol. 2016, 2007, pp 123-138, Elsevier

[22] A. Malek a, M.N.A. Hawlader b, J.C. Ho b "Design and economics of RO seawater desalination", Desalination vol. 105, 1996,pp 245-261, Elsevier

[23] J. Kucera, "Reverse Osmosis-Design, Processes, and Applications for Engineers", Scrivener Publishing LLC, U.S. 2010, Salem, Massachusetts

[24] DM 06/07/2012, Ministero dello Sviluppo Economico

[25] Delibera 570/2012/R/ef, Gestore dei Servizi Energetici S.p.A. (GSE).

[26] M. Holmgren, "Water and steam properties according to IAPWS IF-97", www.x-eng.com 